\section{ECONOMICS}

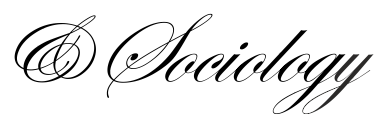

Stefko, R., Gavurova, B., Rigelsky, M., \& Ivankova, V. (2019). Evaluation of selected indicators of patient satisfaction and economic indices in OECD country. Economics and Sociology, 12(4), 149-165. doi:10.14254/2071-

789X.2019/12-4/9

\title{
EVALUATION OF SELECTED INDICATORS OF PATIENT SATISFACTION AND ECONOMIC INDICES IN OECD COUNTRY
}

\author{
Robert Stefko, \\ University of Prešov in Prešov, \\ Presov, Slovakia \\ robert.stefko@unipo.sk. \\ Beata Gavurova,
Tecbnical University of Kosice,
Kosice, Slovakia,
beata.gavurova@tuke.sk \\ Martin Rigelsky, \\ University of Prešov in Prešov, \\ Presov, Slovakia \\ martin.rigelsky@gmail.com

\begin{abstract}
Viera Ivankova,
University of Prešov in Prešov,

Presov, Slovakia

ivankova.vierka@gmail.com
\end{abstract}

Received: December, 2018

1st Revision: March, 2019

Accepted: October, 2019

DOI: $10.14254 / 2071-$

789X.2019/12-4/9

JEL Classification: I14, I15
ABSTRACT. The primary aim of the research is to estimate the relationship between healthcare indicators and economic indices in the selected OECD countries. The goal was met in three main procedures. Firstly, a cluster of the selected countries was identified, then a relationship analysis was realized on eight variables that determined satisfaction and economic indices (Global Innovation Index - GII, Human Development Index - HDI) and at the end, regression analysis which calculates the impact of innovation activity (GII) on healthcare satisfaction was used (the mean of 8 healthcare satisfaction variables MeanHC) as well as the impact of this variable on maturity (HDI) in the selected OECD countries (the sample of 33 countries). The cluster was estimated by using the method based on Euclidean distance, and the number of clusters was defined by Silhouette method. Two clusters were computed. Also, the coefficients such as Spearman $\rho$ and Pearson $r$ were used in analysis of this relationship. A significant relationship is not evident only in the variable that determined cost satisfaction. The differences between clusters in the individual satisfaction variables were confirmed by t-test, Welch test and Wilcoxon test. A significant difference between the clusters is in satisfaction with staff friendliness. Regression analysis was computed by means of using a method based on Least Trimmed Squares Robust Regression. Significant impact was reflected in both assumptions (GII to MeanHC and also MeanHC to HDI).

Keywords: quality of healthcare, patient satisfaction, OECD, global innovation index, human development index, relations analysis, cluster analysis.

\section{Introduction}

Health of population is an important determinant of economic development because healthy population always means higher productivity (World Health Organisation, 2005). The relationship between economy and public health was examined by quite many authors. Lange et al. (2017), Wang (2018), for example, drew attention to preventive care in the sphere of economy growth. If a country has healthy population, it will also have healthy economy. 
For any meaningful decision being made in the healthcare sector, first of all, it would be necessary to define quality of healthcare. However, defining quality in the healthcare sector is not an easy task. According to Grant (1988), quality of medical care is the capacity of all elements of that care to achieve legitimate medical and non-medical goals. According to Mosadeghrad (2013), quality of healthcare may be defined as consistent patient satisfaction by providing efficacious, effective and efficient healthcare services according to the latest clinical guidelines and standards that meet the needs of patients and satisfy their providers. As we can see, definitions are mostly patient-oriented. Medical facilities should focus on patient satisfaction, but very often these facilities are primarily focused on other goals. In fact, patients' perceptions of physician consultations, provision of information to patients and the environment of delivering services, are the most important determinants of service quality in clinics (Abbasi-Moghaddam et al., 2019). Satisfaction is substantial and is closely related to goodwill (Fedorko et al., 2017).

As mentioned above, there is a relationship between healthcare and economic maturity and quality of healthcare is affected by patient satisfaction. The main part of the research is focused on linking patient satisfaction with the quality of healthcare and the selected economic indicators. This intention will be implemented on the sample of OECD countries.

Nowadays, many international organizations and institutions publish well recognized annual reports focusing on evaluating countries from different perspectives to create rankings of countries based on the effect of a range of various economic and non-economic factors (Kiselakova et al., 2019; Ivanová \& Čepel, 2018; Kiselakova et al., 2018).

The present study evaluates the selected indicators of patient satisfaction and economic indicators of the OECD countries. We have used indicators, such as the HDI and GII index. The importance of innovation is highlighted also by Sofrankova et al. (2018) in the context of the total $R \& D$ expenditure. Their results suggested that growth in $R \& D$ expenditures may significantly contribute to increasing countries' innovation activity level. To better understand the issue, the selected indicators were described. According to the Human Development Report 2016, the HDI index integrates three basic dimensions of human development: i - Life expectancy at birth reflects the ability to lead a long and healthy life, ii Mean years of schooling and the expected years of schooling reflect the ability to acquire knowledge, and iii - Gross national income per capita reflects the ability to achieve decent standards of living (UNDP, 2017). The GII index captures the multidimensional aspects of innovation and provides the tools that may help in tailoring the policies to support long-term output growth, productivity improvements and job growth. The index consists of the following dimensions: i - Institutions, ii - Human capital \& research, iii - Infrastructure, iv Market sophistication, v - Business sophistication, vi - Knowledge \& technology outputs, vii Creative outputs (Cornell University, INSEAD, WIPO, 2018).

\section{Literature review}

Health diversity in OECD countries is a topic that is analyzed in several dimensions. Toth (2018) analyzed the systems of healthcare and how the network of healthcare providers is organized and confirms diversity in 24 OECD countries. Tambor et al. (2011) examined the diversity of health in a topic of patient payments between EU 27. Varabyova et al. (2013) pointed out the diversity of OECD countries based on technical efficiency. Aiken et al. (2012) conducted a study focused on varied substantially by selected OECD country in a topic of medical staff - nurses. Human resources are crucial for the success of any company (Gonos et al. 2018), which also applies to healthcare facilities. Kotulic (2013) also highlights the quality of the work force. Berman (2000) highlights the diversity in ambulatory personal health services. Relatively all these dimensions may be described from the patient's point of view as 
satisfaction with healthcare (Krot \& Rudawska, 2016). Assessment of quality and performance of healthcare based on structure and process do not overlap with the results of the patient evaluation. Therefore, it is also important to take into account patients' preferences, needs and expectations in order to ensure a high quality in the primary care system (Murante et al., 2017). Patient satisfaction is currently seen as an important indicator of health service outcomes; however, this professed utility is based on a number of implicit assumptions about the nature and meaning of 'satisfaction' (Williams, 1994). Monitoring the patient satisfaction is an integral part of monitoring the quality of healthcare (Bris et al., 2016). Patient satisfaction and related activity with this construct represents relatively complex concept. The patient's satisfaction with healthcare may be seen from several points of view. Ross et al. (1993) state that the idea that patients will be more satisfied with the healthcare services provided to meet their preferences is a central element of the healthcare marketing concept and this satisfaction may be determined in three areas $\mathrm{i}$ - interpersonal care, ii - technical quality, iii - access to care. Dagger et al. (2007) identified four primary dimensions that enhance the perception of service quality: i - interpersonal quality, ii - technical quality, iii environment quality, and iv - administrative quality. As important areas of patient satisfaction, Jenkinson et al. (2002) classifies i - physical comfort, ii - emotional support, and iii - respect for patient preferences. Several studies highlight patients' perception of how their care is provided and the positive patient experiences as an assessment of the quality of healthcare (Fernandes et al., 2019; Ahmed et al., 2014; Doyle et al., 2013; Price et al., 2014). Results by Ko et al. (2019) provide strong empirical evidence that operational healthcare inefficiency negatively influences patient satisfaction. Grytten (2009) states that there is a relationship between the level of production of general practitioners' services and patient satisfaction with the waiting time for a consultation. Minimizing the time that patients wait for a provider visit may result in higher overall patient satisfaction scores, regardless of financial status (McMullen \& Netland, 2013). Ursoiu (2018) described the elements of patient satisfaction in the dimension of marketing mix (product, place, price, promotions) and pointed out the principle - The patient is therefore placed at the center of the processes and his satisfaction is held in high regard, in order to ensure an optimal socio-economic development.

The fact that health capital plays a significant role in a country's economic growth from a long-term perspective was confirmed in several studies (Kim et al., 2019; Weil, 2007; Bloom et al., 2004; Hartwig, 2010; Gallardo-Albarran, 2018). Average life expectancy is a commonly used measure of health system efficiency, economic development, and a key indicator of people's well-being. Healthcare spending for countries has heterogeneous effects on life expectancy, due to differences in population characteristics and economic factors (Obrizan \& Wehby, 2018.) Many studies (van Baal \& Wong, 2012; Tobias \& Yeh, 2009; Farag et al., 2013; Obrizan \& Wehby, 2018) evaluated the variation in the impact of healthcare expenditure by using linear regression, and the results showed that increasing health spending in low life-long countries may produce significant returns on the life expectancy of the population, while reducing global inequalities in long-term care. Sharma (2018) conducted a study focusing on influence of population health outputs on their real income. A similar idea is presented in wider optics, the results reported by Boachie (2017) show a positive link between healthcare and economic growth. Gorgulu (2018) confirmed that health indicators have direct effects on countries' income and wealth, labor productivity, demographic structure, and human capital factors. Policy-makers should consider the international health indicators and take the right steps according to citizens' expectation and satisfaction of healthcare service to implement effective spending. Xesfingi et al. (2016) in their research confirmed the link between patient satisfaction and medical personal behavior. The authors also described the finding that socio-economic variables, public health expenditure are largely and positively linked to patient satisfaction. On the other hand, there 
are Acemoglu and Johnson's (2007) findings that health improvements may have lowered the pace of economic growth. Yagudin et al. (2016) dealt with the role of health capital and innovation in human development, where as a dependent variable HDI is used. Findings by Babiarz et al. (2018) reveal that the health does not have the greatest impact on socioeconomic development represented by the customized HDI.

Many health economists believe that technological change is the major factor driving the growth of the healthcare sector. Medical innovations have improved the treatment of many diseases, but simultaneously, they have raised healthcare expenditure. Whether quality has increased as well as expenditure is a central question of the study by Hult et al. (2018). Several authors dealt with health innovations and its impact on the quality of healthcare, for example Agha (2014) conducted research focused on health information technology and Mickan et al. (2013) identified the effectiveness of handheld computers in clinical practice. A significant part of achieving universal health coverage for patients is to ensure access to quality of healthcare for the whole population in many countries and to increase technological innovation. It is important to look at the field of profits made or advances in healthcare, where access to healthcare is crucial to managing decisions and strategies for future improvements in the quality of the health system (Doubova \& Pérez-Cuevas, 2018). On the other hand, the findings by Alhassan et al. (2019) suggest that increased efforts towards technical quality care alone will not necessarily translate into better client-perceived quality care and willingness to utilize health services.

\section{Methodological approach}

The goal was met in three main procedures. Firstly, the cluster of selected countries was determined, then the relationship analysis was realized and at the end, the regression analysis to calculate impact of innovations activity (GII) on satisfaction with healthcare was used (MeanHC). Also, impact of this variable on maturity (HDI) in selected OECD country was researched.

The research sample included selected OECD countries. Asian countries (Japan, Korea) were not included in the analysis, these countries are different from others, as well. As Lithuania became a full member on 5 July 2018 after data collection, it was excluded from the analysis. A total of 33 countries were analyzed, including Australia (AUS) Austria (AUT), Belgium (BEL), Canada (CAN), Chile (CHL), Czech Republic (CZE), Denmark (DNK), Estonia (EST), Finland (FIN), France (FRA), Germany (DEU), Greece (GRC), Hungary (HUN), Iceland (ISL), Ireland (IRL), Italy (ITA), Israel (IRL), Latvia (LVA), Luxembourg (LUX), Mexico (MEX), Netherlands (NDL), New Zealand (NZL), Norway (NOR), Poland (POL), Portugal (POR), Slovak Republic (SVK), Slovenia (SVN), Spain (ESP), Sweden (SWE), Switzerland (SWZ), Turkey (TUR), United Kingdom (GBR), United States (USA). Relevant data were collected in 2018, variables described the perceptual value of satisfaction. All variables are on a percentage scale where higher output indicates better rating of the given variable. There are 8 variables (NUMBEO (2018)): i - Skill and competency of medical staff (skill), ii - Speed in completing examination and reports (speed), iii - Equipment for modern diagnosis and treatment (eqt), iv - Accuracy and completeness in filling out reports (reports), v - Friendliness and courtesy of the staff (staff FS), vi - Satisfaction with responsiveness (waitings) in medical institutions (answ_T), vii - Satisfaction with cost to you (cost), viii Convenience of location for you (place).

The analysis included also variables that express the country's maturity (HDI) and innovation activity (GII). These indices were selected based on their high informative value it was described in theoretical background. The HDI and GII were used for regression analysis that defines the impact on health (mean of selected health variable). All variables 
may be graded on a percentage scale where higher output indicates better rating of the given variable.

\section{Conducting research and results}

Through the quantitative part of the research, the focus was on data collecting, processing, and analysis. A nine-level Likert scale was used to measure the perceptions and assessments of the respondents, on the dependent variable (transitional crisis), as well as the independent variables (heritage of socialism, geopolitics, nomenclature authorities, deficit of institutional changes, and neoliberal ideology), in a survey that was applied during the research. In measuring the dependent variable (transitional crisis), the scale marks were set from the lowest (1) to the highest (5). Regarding the independent variables, the negative impact was measured from the minimum negative (1) to the maximum (5) on the dependent variable. The survey included filling out 500 questionnaires for each country (Montenegro, Serbia, and Bosnia and Herzegovina), which made a total of 1.500 respondents. Collected data for this study were processed by SPSS software. According to the purpose defined in the hypothesis of work, descriptive statistics were used for the data analysis, correlation analysis, and multi-correlation. The multiple linear regression model was applied after (the method of least square), as well as hierarchical multiple regression model.

Based on the set goals, the hierarchical cluster analysis was used for data processing, a data-aggregation method, using the Between group in which the distance based on the Euclidean distance was defined. Optimal number of clusters was estimated using Silhouette method (Rousseeuw, 1987). The differences between clusters were compared where t-test (Welch test) was used. Normality was verified with Shapiro-Wilk's test and homogeneity of variance with Levene test. The method of filling the secondary goal was the correlation analysis where the nonparametric Spearman's $\rho$ or parametric method Perason $r$ were used. This correlation coefficient was chosen based on multivariate normality outputs calculated by Henze-Zirkler's multivariate normality test and multivariate outliers' detections quantile method based on Mahalanobis distance. The following section analyzed the impact of healthcare outputs on HDI and GII. This impact was analyzed using Least Trimmed Squares Robust Regression. Into analysis as independent variable entered variable represent average output of healthcare. This variable is de facto mean of selected healthcare outputs (skill, speed, eqt, reports, staff_FS, waitings, answ_T, cost, place). The procedure for calculating the arithmetic mean was chosen based on high multi-collinearity of the independent variables. Multi-collinearity was tested using the Variance inflation factor (VIF $<5$ (10) - good collinearity is less than 5, acceptable rate is 10 ). The possibility of using the arithmetic mean is conditioned sufficient height reliability of more than 0.7 (minimum acceptable rate), for reliability analysis was used Cronbach's methods - coefficient $\alpha$. On the basis of previous outputs, a panel regression analysis may be used, but output of $F$ test for individual effects is recommended simple linear regression. Gauss-Markov theorem for BLUE (Best Linear Unbiased Estimate) in samples with many observations speaks within the bounds of a regression model mainly about the heteroscedasticity assumptions (big sample - generally, more than 30 observation). The main condition that was verified is the homoscedasticity (constant variability of residues) of the assumptions that were verified by the Breusch-Pagan test. Secondly, normality and outliers were processed with the help of the quantile plot and Bonferroni Outlier Test. All analytical procedure was made with help statistical language R.

\subsection{Application of Cluster Analysis}


In cluster analysis is usually a problem to define optimal number of clusters. There was used Silhouette method to define optimal number of clusters, the output is presented below in Figure 1.

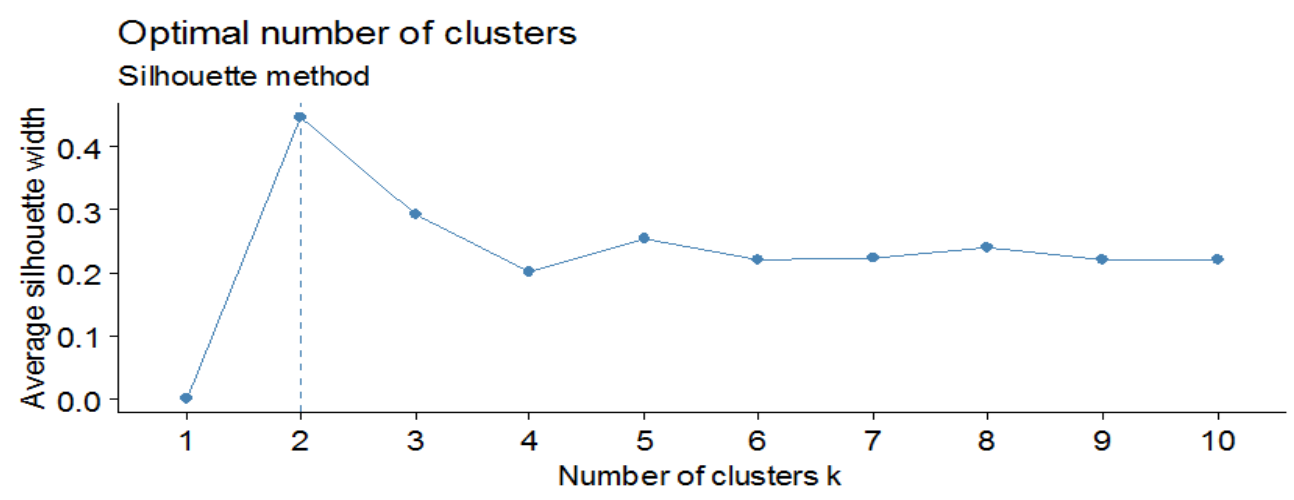

Figure 1. Optimal number of clusters

Source: own data

Based on the previously Figure 1, the conclusion was that the optimal number of clusters is 2 . As the essence of cluster analysis is known, it defines common groups of states based on the smallest variation within the group as possible and the biggest difference between groups. The following dendrogram (Figure 2) presents the outputs.

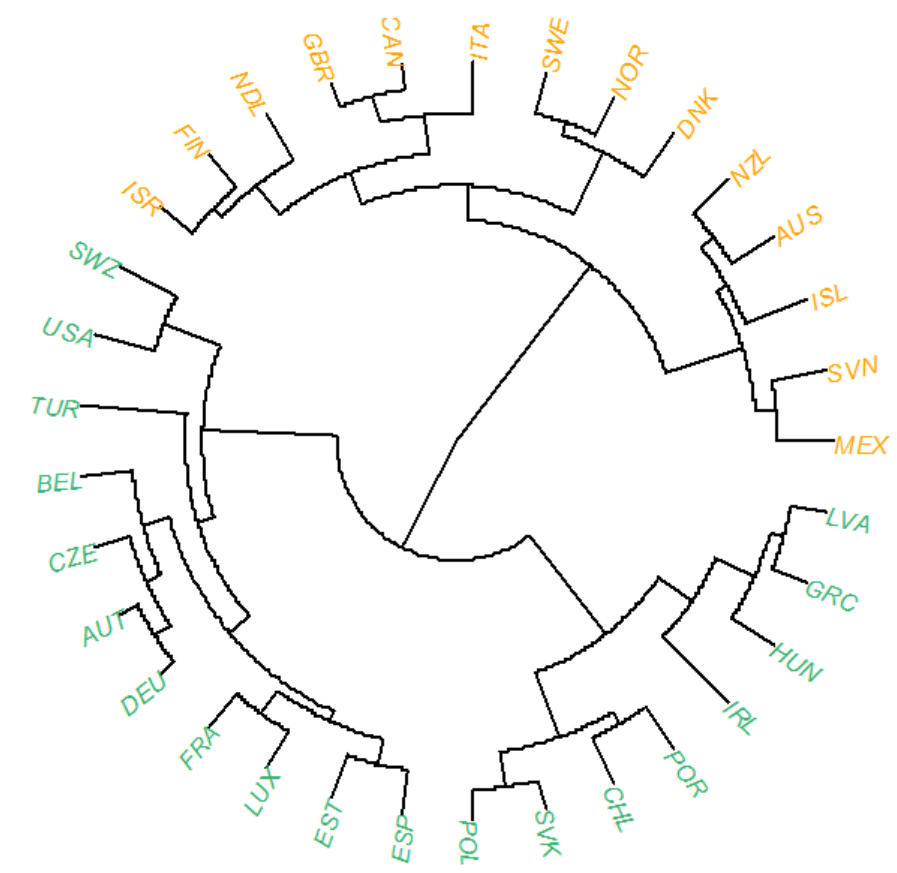

Figure 2. Circle dendrogram using - Based on Euclidean distance. Source: own processing. Source: own data

Previous outputs of Figure 2 visualize the similarity of countries based on the above variables. The cluster one (Cl. 1) is formed by countries such as Australia, Canada, Denmark, Finland, United Kingdom, Ireland, Israel, Italy, Mexico, Netherlands, Norway, New Zealand, Slovenia, Sweden and next cluster two (Cl. 2) is formed by countries such as Austria, Belgium, Czech Republic, Germany, Spain, Estonia, France, Greece, Hungary, Chile, Iceland, 
Luxembourg, Latvia, Poland, Portugal, Slovak Republic, Switzerland, Turkey, United States. In general, it may be assumed that the "proximity" of the countries may be made up of their maturity. Previous outputs do not tell which cluster is better, or which cluster is getting better ratings, this information is provided by the following Table 1.

Table 1. Evaluation of clusters - descriptive statistic

\begin{tabular}{rlrrrrrrrr}
\hline & & Skill & \multicolumn{1}{c}{ Speed } & \multicolumn{1}{c}{ Eqt } & reports & staff_FS & Answ_T & Cost & \multicolumn{1}{c}{ Place } \\
\hline \multirow{3}{*}{ Cl. 1} & $\mathrm{M}$ & 73.18 & 63.56 & 83.68 & 71.49 & 73.83 & 51.68 & 73.34 & 78.30 \\
\cline { 2 - 11 } & $\mathrm{n}$ & 14 & 14 & 14 & 14 & 14 & 14 & 14 & 14 \\
\cline { 2 - 11 } & SD. & 7.03 & 9.47 & 7.47 & 6.55 & 6.15 & 12.07 & 10.73 & 5.35 \\
\hline \multirow{3}{*}{ Cl. 2} & $\mathrm{M}$ & 73.24 & 65.20 & 80.28 & 70.13 & 66.15 & 52.62 & 66.67 & 78.66 \\
\cline { 2 - 10 } & $\mathrm{n}$ & 19 & 19 & 19 & 19 & 19 & 19 & 19 & 19 \\
\cline { 2 - 10 } & SD. & 8.00 & 12.54 & 12.86 & 8.90 & 10.19 & 14.07 & 13.42 & 6.64 \\
\hline \multirow{3}{*}{ Total } & $\mathrm{M}$ & 73.22 & 64.50 & 81.72 & 70.71 & 69.41 & 52.22 & 69.50 & 78.51 \\
\cline { 2 - 10 } & $\mathrm{n}$ & 33 & 33 & 33 & 33 & 33 & 33 & 33 & 33 \\
\cline { 2 - 9 } & SD. & 7.49 & 11.21 & 10.89 & 7.91 & 9.42 & 13.07 & 12.62 & 6.04 \\
\hline
\end{tabular}

Source: own compilation

Based on previous outputs, two clusters are the best solution for the research. As it is presented below, in many cases, there is not essential difference between clusters. The significance of the differences was verified by t-test. Normality was verified by Shapiro-Wilk test and homogeneity of variance with Levene test.

Table 2. Output of differences with assumptions testing

\begin{tabular}{|c|c|c|c|c|c|}
\hline Satisfaction & Cluster & $\begin{array}{r}\text { Shapiro-Wilk } \\
\text { p value }\end{array}$ & $\begin{array}{r}\text { Levene test } \\
\text { p value }\end{array}$ & Two Sample & $p$ value \\
\hline \multirow{2}{*}{ Skill } & 1 & 0.0739 & \multirow{2}{*}{0.4649} & \multirow{2}{*}{ T-test } & \multirow{2}{*}{0.9807} \\
\hline & 2 & 0.3671 & & & \\
\hline \multirow{2}{*}{ Speed } & 1 & 0.9781 & \multirow{2}{*}{0.3395} & \multirow{2}{*}{ T-test } & \multirow{2}{*}{0.6863} \\
\hline & 2 & 0.6304 & & & \\
\hline \multirow{2}{*}{ Eqt } & 1 & 0.2126 & \multirow{2}{*}{0.0405} & \multirow{2}{*}{ Welch test } & \multirow{2}{*}{0.3478} \\
\hline & 2 & 0.0451 & & & \\
\hline \multirow{2}{*}{ reports } & 1 & 0.3939 & \multirow{2}{*}{0.1953} & \multirow{2}{*}{ T-test } & \multirow{2}{*}{0.6349} \\
\hline & 2 & 0.2096 & & & \\
\hline \multirow{2}{*}{ staff_FS } & 1 & 0.3881 & \multirow{2}{*}{0.0481} & \multirow{2}{*}{ Welch test } & \multirow{2}{*}{0.0117} \\
\hline & 2 & 0.7332 & & & \\
\hline \multirow{2}{*}{ answ_T } & 1 & 0.9170 & \multirow{2}{*}{0.4018} & \multirow{2}{*}{ T-test } & \multirow{2}{*}{0.8418} \\
\hline & 2 & 0.7669 & & & \\
\hline \multirow{2}{*}{ cost } & 1 & 0.0094 & \multirow{2}{*}{$\mathrm{x}$} & \multirow{2}{*}{ Wilcoxon test } & \multirow{2}{*}{0.1418} \\
\hline & 2 & 0.4509 & & & \\
\hline \multirow{2}{*}{ place } & 1 & 0.0415 & \multirow{2}{*}{$\mathrm{x}$} & \multirow{2}{*}{ Wilcoxon test } & \multirow{2}{*}{0.6794} \\
\hline & 2 & 0.2586 & & & \\
\hline
\end{tabular}

Source: own compilation

The use of the t-test is conditioned by meet of the assumptions, such as normality and homogeneity of variance. As it may be seen in the Table 2, the assumptions of approximately normality are met in the vast majority ( $p$-value is more than 0.05), so the parametric differences test may be used. Normality is not met in two cases ( $p$ value is less than 0.05 ). In these two cases nonparametric Wilcoxon two samples test was used. The assumptions of homogeneity variances are not met in two cases ( $p$-value is less than 0.05 ), so Welch test was used. As itmay be seen, there is a significant difference in only one case - staff_FS. The difference is shown in the following Figure 3. 


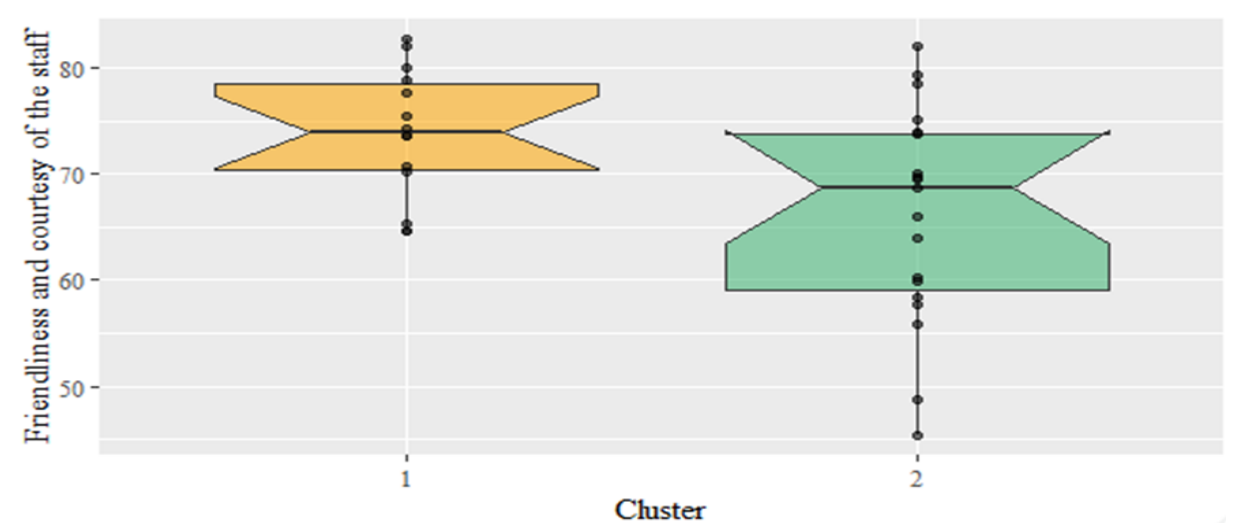

Figure 3. Optimal number of clusters Source: own data

Figure 3 indicates that cluster one reached better output than cluster two. Based on the results, hospital staff in countries, such as Australia, Canada, Denmark, Finland, United Kingdom, Ireland, Israel, Italy, Mexico, Netherlands, Norway, New Zealand, Slovenia or Sweden is more friendly then in other analyzed countries. In the following sections, there was an attempt to prove the dependence of the health and health outcomes of a given sample.

\subsection{Application of Correlation analysis}

As already mentioned, the following section focuses on verifying the relationship between country maturity, innovation activity, and health outcomes. The maturity of a given country was defined by using an aggregated variable the HDI index and innovation activity through the GII index. The optimal method to calculate the relationship was chosen based on the output of multivariate normality (MVN) and information about significant outliers. Thus, Henze-Zirkler's multivariate normality test (HZ) and quantile method based on Mahalanobis distance (outliers) were used. The results are shown in the following Table 3.

Table 3. Assumptions testing

\begin{tabular}{|c|c|c|c|c|c|c|c|c|c|c|c|c|}
\hline & Index & HZ & p value & MVN & outliers & Coef & Index & HZ & p value & MVN & outliers & Coef \\
\hline skill & HDI & 1.0245 & $1.29 \times 10^{-2}$ & $\mathrm{NO}$ & YES & $\rho$ & GII & 0.7350 & $8.53 \times 10^{-2}$ & YES & YES & $\rho$ \\
\hline speed & HDI & 0.7074 & $1.02 \times 10^{-1}$ & YES & YES & $\rho$ & GII & 0.3444 & $7.23 \times 10^{-1}$ & YES & $\mathrm{NO}$ & $r$ \\
\hline eqt & HDI & 1.6590 & $2.53 \times 10^{-4}$ & $\mathrm{NO}$ & YES & $\rho$ & GII & 1.0895 & $8.45 \times 10^{-3}$ & $\mathrm{NO}$ & YES & $\rho$ \\
\hline reports & HDI & 1.0628 & $1.00 \times 10^{-2}$ & $\mathrm{NO}$ & YES & $\rho$ & GII & 0.6838 & $1.18 \times 10^{-1}$ & YES & YES & $\rho$ \\
\hline staff_FS & HDI & 1.7331 & $1.65 \times 10^{-4}$ & $\mathrm{NO}$ & YES & $\rho$ & GII & 0.6645 & $1.34 \times 10^{-1}$ & YES & YES & $\rho$ \\
\hline answ_T & HDI & 0.8070 & $5.35 \times 10^{-2}$ & YES & YES & $\rho$ & GII & 0.3813 & $6.29 \times 10^{-1}$ & YES & $\mathrm{NO}$ & $r$ \\
\hline $\operatorname{cost}$ & HDI & 1.5351 & $5.26 \times 10^{-4}$ & $\mathrm{NO}$ & YES & $\rho$ & GII & 1.3245 & $1.90 \times 10^{-3}$ & $\mathrm{NO}$ & YES & $\rho$ \\
\hline place & HDI & 1.2258 & $3.53 \times 10^{-3}$ & $\mathrm{NO}$ & YES & $\rho$ & GII & 0.6713 & $1.28 \times 10^{-1}$ & YES & YES & $\rho$ \\
\hline
\end{tabular}

Source: own compilation

The assumptions of normality are not met when p-value of MVN is less than 0.05 and if there were any significant outliers, Spearman nonparametric coefficient $\rho$ was used. In other cases, parametric coefficient Pearson $r$ was used. The above coefficient is based on hypotheses: $\mathrm{H}_{0}: \rho=0 ; \mathrm{H} 1: \rho \neq 0$.

Thus, there is no significant relationship of the given variables in the HO hypothesis and, alternatively, the assumption of $\mathrm{H} 1$ is significant. The following Table 4 shows the test results. 
Table 4. Relationship (correlation) of aggregate economic indicators (HDI, GII) and selected indicators of healthcare

\begin{tabular}{|c|c|c|c|c|c|c|c|c|c|}
\hline & & Skill & Speed & Eqt & reports & staff_FS & Answ_T & Cost & Place \\
\hline \multirow{2}{*}{ HDI } & Correlation & 0.4205 & 0.3549 & 0.5059 & 0.4372 & 0.7263 & 0.3777 & $\mathrm{x}$ & 0.5110 \\
\hline & Sig. & $1.55 \times 10^{-2}$ & $4.33 \times 10^{-2}$ & $2.67 \times 10^{-3}$ & $1.16 \times 10^{-2}$ & $3.90 \times 10^{-6}$ & $3.10 \times 10^{-2}$ & $4.34 \times 10^{-1}$ & $2.69 \times 10^{-3}$ \\
\hline \multirow{2}{*}{ GII } & Correlation & 0.4036 & $0.4060 *$ & 0.6106 & 0.4648 & 0.6272 & $0.4513 *$ & $\mathrm{x}$ & 0.5166 \\
\hline & Sig. & $1.99 \times 10^{-2}$ & $1.91 \times 10^{-2}$ & $1.61 \times 10^{-4}$ & $6.43 \times 10^{-3}$ & $9.37 \times 10^{-5}$ & $8.38 \times 10^{-3}$ & $1.47 \times 10^{-1}$ & $2.09 \times 10^{-3}$ \\
\hline
\end{tabular}

Source: own compilation

The first row of the HDI or GII variables in Table 4 provides the information and magnitude of the correlation coefficient of the monotonic and rank order nonparametric relationship of Spearman $\rho$ or parametric Pearson $r$. The second row shows the asymptotic significance, the p-value. In HDI, the p-value is higher than 0.05 only in the case of Cost variables (Satisfaction with the cost to you) and the p-value of GII variable is higher than 0.05 in the same case - Cost. These cases indicate that the measured relationship is not statistically significant, so in these cases, the H0 hypothesis is not disputed. In all other cases, it is recommended not to reject the $\mathrm{H} 1$ hypothesis, meaning, a statistically significant relationship of given variables. Cases where the relationship is not significant may be due to the forms (systems) of financial aspects of particular countries (Lakomy-Zinowik \& Horváthová, 2016). The value of correlations, when the relationship is significant, may be interpreted as moderate to strong relationship according to De Vaus (2002).

The above results confirm the relationship between selected elements. In the case of the HDI variable, the strongest relationship was shown with the Friendliness and courtesy of the staff. Consequently, the more developed country, the friendlier medical staff. This relationship was defined by the p-value of 0.726 , which was interpreted as a very strong dependence. The second highest rating was the variable - place with a p-value of 0.511 , which was characterized as essential to strong dependence. Staff_FS also showed the highest p-value (0.627) in the case of the GII variable, which was expected. In this innovation indicator, a relatively high degree of dependence was also demonstrated by the variables Equipment for Modern Diagnosis and Treatment with a $\rho$-value 0.611 , which is characterized by a high dependence. The more a country develops more innovative activities, the more it is reflected in the hospital technology, symbolized by the variable Equipment for modern diagnosis and treatment

\subsection{Application analysis of impact}

The following section determines the impact of healthcare satisfaction variables on the HDI and the GII indicators. The regression model was used where one or few assumptions of multi-collinearity existed.

Table 5. Assumptions of multi-collinearity - Variance inflation factor

\begin{tabular}{llllrrrrr}
\hline & Skill & Speed & Eqt & \multicolumn{1}{c}{ reports } & \multicolumn{1}{c}{ staff_FS } & \multicolumn{1}{c}{ Answ_T } & \multicolumn{1}{c}{ Cost } & Place \\
\hline VIF & 20.4577 & 14.2348 & 14.1250 & 34.1737 & 2.3046 & 11.0686 & 1.80983 & 6.9596 \\
\hline
\end{tabular}

Source: own compilation

Based on the previous Table 5, the model may consist of only three variables of all the selected variables (staff_FS, Cost, Place). In the next step, the average of variables was applied and creating a new variable expressing overall satisfaction with the quality of healthcare - MeanHC. The possibility of using this procedure is demonstrated by the 
Cronbach's Alpha reliability test. The output of this test is equal to 0.92 (Very good), which tells about the applicability of the above-mentioned procedure. The column - MeanHC in the following Table 7 provides an aggregated assessment of healthcare satisfactions for selected countries. The HDI and GII columns show the Human Development Index and the Global Innovation Index for each countries.

Table 6. Presentation of data entering into regression analysis

\begin{tabular}{|c|c|c|c|c|c|c|c|c|c|}
\hline Country & ID & HDI & GII & MeanHC & Country & ID & HDI & GII & MeanHC \\
\hline Australia & AUS & 93.87 & 51.80 & 76.97 & Latvia & LVA & 82.99 & 44.60 & 55.05 \\
\hline Austria & AUT & 89.34 & 53.10 & 78.79 & Luxembourg & LUX & 89.85 & 56.40 & 77.11 \\
\hline Belgium & BEL & 89.55 & 49.90 & 81.26 & Mexico & MEX & 76.17 & 35.80 & 68.77 \\
\hline Canada & CAN & 92.03 & 53.70 & 69.36 & Netherlands & NDL & 92.43 & 63.40 & 81.97 \\
\hline Czech Republic & $\mathrm{CZE}$ & 87.78 & 51.00 & 74.16 & New Zealand & NZL & 91.49 & 52.90 & 72.37 \\
\hline Denmark & DNK & 92.46 & 58.70 & 75.15 & Norway & NOR & 94.94 & 53.10 & 74.03 \\
\hline Estonia & EST & 86.51 & 50.90 & 71.12 & Poland & POL & 85.52 & 42.00 & 61.83 \\
\hline Finland & FIN & 89.45 & 58.50 & 75.55 & Portugal & POR & 84.27 & 46.10 & 69.29 \\
\hline France & FRA & 89.74 & 54.20 & 77.66 & Slovak Republic & SVK & 84.49 & 43.40 & 63.32 \\
\hline Germany & DEU & 92.57 & 58.40 & 75.89 & Slovenia & SVN & 89.03 & 45.80 & 63.22 \\
\hline Greece & GRC & 86.59 & 38.80 & 53.83 & Spain & ESP & 88.42 & 48.80 & 76.34 \\
\hline Hungary & HUN & 83.62 & 41.70 & 49.81 & Sweden & SWE & 91.27 & 63.80 & 69.29 \\
\hline Chile & CHL & 84.66 & 38.70 & 63.98 & Switzerland & SWZ & 93.91 & 67.70 & 75.34 \\
\hline Iceland & ISL & 92.11 & 55.80 & 66.67 & Turkey & TUR & 76.70 & 38.90 & 70.77 \\
\hline Ireland & IRL & 92.27 & 58.10 & 54.21 & United Kingdom & GBR & 90.95 & 60.90 & 73.14 \\
\hline Israel & ISR & 89.89 & 53.90 & 74.14 & United States & USA & 91.96 & 61.40 & 71.03 \\
\hline Italy & ITA & 88.66 & 47.00 & 67.68 & & & & & \\
\hline
\end{tabular}

Source: own compilation

The previous Table 6 describes the variables that entered the regression analysis, but also completes the overall picture of the issue. At the end of the previous section, the relationship between individual health outcomes and outcomes of maturity and innovation activity was drawn.

As it was already mentioned, the relationship was confirmed between several variables expressing the level of healthcare, in some cases it was weaker, in some stronger. The question remains, what is the strength of the relationship with a few times mentioned aggregated variable expressing the level of healthcare and the maturity or innovation activity of the country.

For a proper impact assessment, it was necessary to choose a suitable model. It was decided between a simple regression model and a panel model. The clusters of countries that were described in section 3.1 - Cluster Analysis enter the panel model.

Two regression models (OLS, fixed effect model) were compared to select the model correctly. To compare the OLS and fixed model, the F test for each effect was used. When testing the HDI as a dependent variable, the p-value for OLS and fixed model was approximately equal to $0.08504(\mathrm{~F}=3.172)$ and when was tested the GII the p-value was approximately equal to $0.5715(\mathrm{~F}=0.32728)$. Thus, the statistical hypothesis $\mathrm{H} 0$ (H0: nonsignificant effects of factor (cluster) variable) may not be rejected, in both cases, the OLS model was accepted as better for use than Fixed effect model.

Theoretically, two models were considered:

Model 1: HDIi $=\alpha+\beta$ MeanHCi $+\varepsilon i$

Model 2: MeanHCi $=\alpha+\beta$ GIIi $+\varepsilon i$

for each of them the statistical hypothesis was assumed:

$\mathrm{H} 0$ : there is no impact predictor to dependent variable. 
$\mathrm{H} 1$ : there is impact predictor to dependent variable.

The Gauss-Markov theorem for BLUE (Best Linear Unbiased Estimator) says that in simple linear regression models (including the used models), the assumptions of constant variability of residuals - heteroscedasticity should be met (in large sample data). The assumptions of homoscedasticity were verified by using the Breusch-Pagan test. Model 1 reached the output of BP statistic equal to 0.18401 and the p-value was equal to 0.6679 . Model 2 reached the output of BP statistic equal to 0.34531 and the p-value was equal to 0.5568 . The assumptions of constant residual variability were met in both cases. The p-value was less than 0.05 in both cases, therefore, $\mathrm{H} 0$ was not rejected (H0: residual variability is constant). For correctly estimated models, the outliers were analyzed. The following Figure 4 shows the quantile plot.
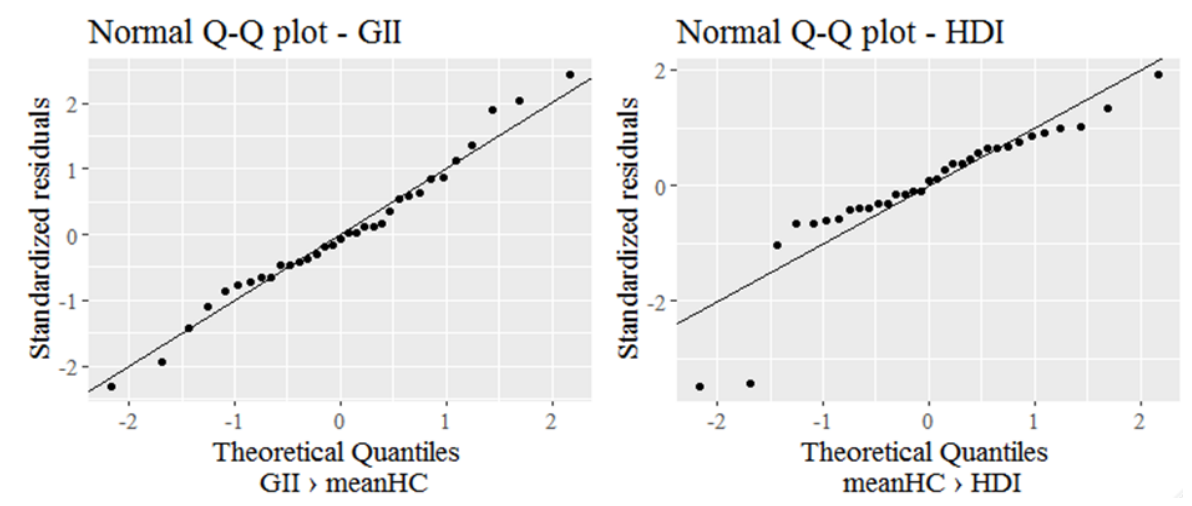

Figure 4. Visualizations of outliers and normality

Source: own data

The previous Figure 4 shows normality (point of deviation from the line) on the one hand and the outliers on the other hand. The outliers are evident in the case of HDI. The significance of outliers was tested using the Bonferroni Outlier Test and in both cases the results show the significant outliers. One country in Model 1 (Mexico) and one country in Model 2 (Ireland). Based on this, the impact was estimated by using the Least Trimmed Squares Robust Regression.

Table 7. Regression model output

\begin{tabular}{clllll}
\hline & & Estimate & Std. Error & t value & $\operatorname{Pr}(>|t|)$ \\
\hline \multirow{2}{*}{ Model 1 (HDI) } & (Intercept) & 76.1504 & 4.2963 & 17.7250 & $2.00 \times 10^{-16}$ \\
\cline { 2 - 6 } & MeanHC & 0.1916 & 0.0610 & 3.142 & $3.84 \times 10^{-3}$ \\
\hline $\begin{array}{c}\text { Model 2 } \\
\text { MeanHC) }\end{array}$ & (Intercept) & 40.9802 & 7.0387 & 5.822 & $2.29 \times 10^{-6}$ \\
\cline { 2 - 5 } & GII & 0.5749 & 0.1356 & 4.240 & $1.96 \times 10^{-4}$ \\
\hline
\end{tabular}

Source: own compilation

Model 1 reached the F-statistic value of 9.874 and this model is demonstrably significant at the level of asymptotic significance of 0.003843 . This model reached the value of coefficient of determination (R2) equal to 0.254; that was stated as not very high rate. Model 2 reached the F-statistic value of 17.98 and this model is demonstrably significant at level of asymptotic significance of 0.0001965 . This model reached the value of coefficient of determination (R2) equal to 0.3464. This rate is enough to acceptance it. Both models are significant, because p-value is less than 0.05 , so the alternative statistical hypothesis $\mathrm{H} 1$ was not rejected (H1: there is impact predictor to dependent variable). Based on the above, the opinion that the satisfaction of quality of healthcare significantly affects the maturity (HDI) and the innovations (GII) of selected countries was accepted. 


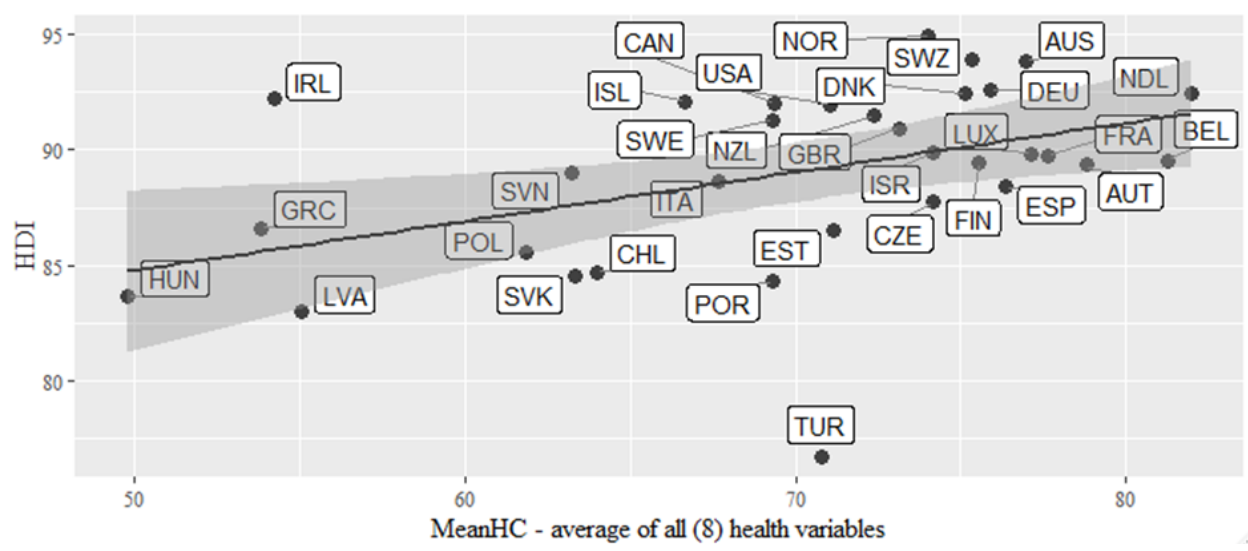

Figure 5. Relations between the HDI index and mean of selected indicators of healthcare (MeanHC).

Source: own data

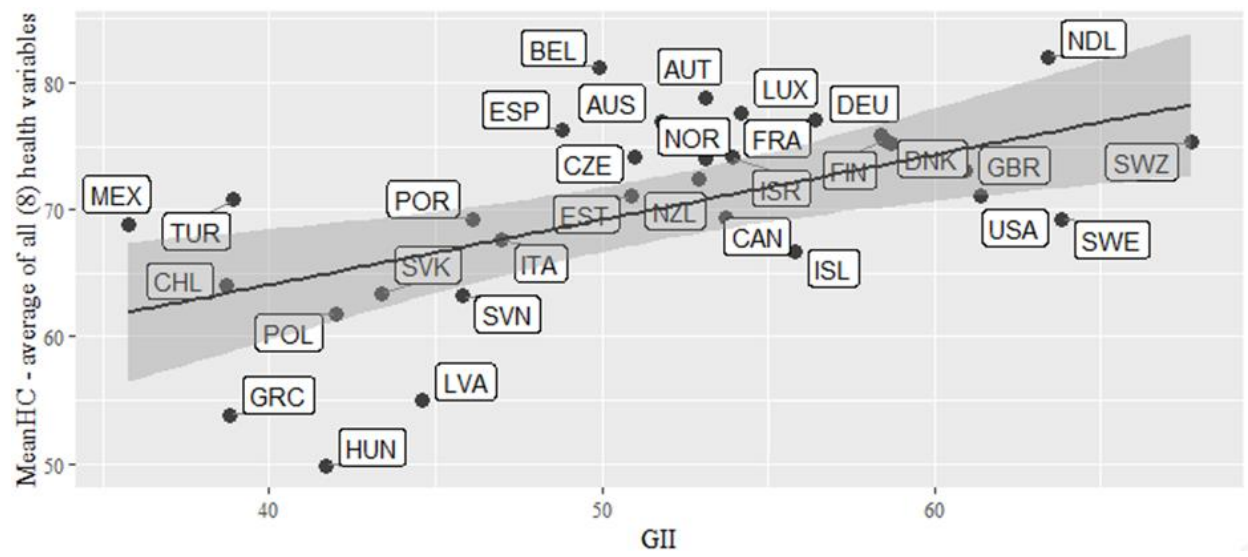

Figure 6. Relations between the mean of selected indicators of healthcare (MeanHC) and GII index.

Source: own data

The previous Figures 5 and 6 illustrate the links between the average of selected healthcare outcomes evaluations and selected economic outcomes. These figures are the visual output of Model 1 and Model 2.

\section{Discussion and conclusions}

Healthcare may be seen as an important and often very "painful" element of the economy. The primary aim of the research is to estimate the relationship between healthcare indicators and economic indices in selected OECD (33) countries. The goal was met in three main procedures. At first, a cluster of selected countries was determined, then a relationship analysis was realized and at the end, the regression analysis was used to calculate the impact of innovation activity (GII) on the satisfaction with healthcare (MeanHC), and also the impact of this variable on maturity (HDI) in selected OECD countries. Output of the cluster analysis (selected indicators of healthcare satisfaction) determined two clusters. The first cluster consists of countries, such as Australia, Canada, Denmark, Finland, United Kingdom, Ireland, Israel, Italy, Mexico, Netherlands, Norway, New Zealand, Slovenia, Sweden and the second cluster includes countries, such as Austria, Belgium, Czech Republic, Germany, Spain, Estonia, France, Greece, Hungary, Chile, Iceland, Luxembourg, Latvia, Poland, Portugal, Slovak Republic, Switzerland, Turkey, United States. This may be seen in Figure 2. 
Difference test of selected indicators was applied between clusters in the next step. A significant difference was only in variable represented by the staff friendliness, when the better output was in cluster one. Output of test may be seen in Table 2 and Figure 3. Aiken et al. (2012) talks about the importance of hospital staff (nurses) friendliness and this importance was confirmed, too. It may be stated that the more developed countries have better output in staff friendliness. However, presented difference could be caused by many other effects based on the specificities of countries, e.g. funding system, culture etc. In the next part of analysis, a bivariate correlation between the GII and HDI was done on the one hand, and selected indicators of healthcare satisfaction on the other hand. The relationship (moderate to strong) was significant in most cases, the insignificant relationship was indicated in only one case cost. This may be seen in Table 4. There are many reasons to explain this outcome, however, the main reason for the difference is the type of funding and financial system of healthcare. According to the primary aim, the analysis of impact was used in the last step where two models were created. One model is the impact of innovation (GII) on satisfaction with healthcare and the other is the impact of healthcare satisfaction on maturity (HDI). Both models showed a significant positive impact. This outcome is in line with the assumption of Boachie (2017) who confirmed the positive link between healthcare and economic growth. This output may be seen in Table 6 and Figures 4 and 5. Thus, in OECD countries with high innovation activities, it is possible to expect high rate of healthcare satisfaction and vice versa. In OECD countries with high healthcare satisfaction, high maturity may be expected and obviously, vice versa.

Babiarz et al. talks about not very strong relations between health and maturity of economy. In the outcomes of analyzes, the strength of the relationship is questionable, but there are evident significant relations. Output of the analysis secondary confirm ideas about importance of innovations in healthcare, which was presented Mickan et al. (2013) and Agha (2014).

From the point of view of research, the primary topic of staff friendliness was highlighted. This part is very important for many elements of healthcare. As already mentioned, hospital staff friendliness is positively linked to health and, in general, healthcare satisfaction. The results also show a strong relationship to economic output. At this point, the importance of innovative activities that have an impact on health care satisfaction and healthcare satisfaction has an impact on the maturity of economy needs to be emphasized. Finally, the innovations in health care that are close to the maturity of economy are important.

The limitation of the statistical view is primarily in the effect size, which is not high. This limitation is due to sample size. In the small sample size, the tests which were used had a tendency to confirm the statistical hypothesis $\mathrm{H} 0$ (do not confirm the difference, relationship, impact etc.). However, in the results, many cases of relation have been confirmed. In the case of a larger sample, stronger relations may be expected. The sample is limited in selection of countries - the output may be generalized to OECD countries. In the future, focus will be put on research with larger sample and different countries.

\section{Acknowledgement}

This work is supported by the Scientific Grant Agency of the Ministry of Education, Science, Research, and Sport of the Slovak Republic and the Slovak Academy Sciences as part of the research project VEGA 1/0846/18: Evaluation of the Efficiency of Public Procurement of Selected Commodities in Healthcare facilities in the Slovak Republic. 


\section{References}

Abbasi-Moghaddam, M.A., Zarei, E., Bagherzadeh, R., Dargahi, H., Farrokhi, P. (2019). Evaluation of service quality from patients' viewpoint. BMC Health Services Research, 19(Article Num 170), doi: 10.1186/s12913-019-3998-0.

Acemoglu, D., \& Johnson, S. (2007). Disease and development: The effect of life expectancy on economic growth. Journal of Political Economy, 115(6), 925-985, doi: $10.1086 / 529000$.

Agha, L. (2014). The effects of health information technology on the costs and quality of medical care. Journal of Health Economics, 34, 19-30.

Ahmed, F., Burt, J., \& Roland, M. (2014). Measuring patient experience: concepts and methods. The Patient 7(3), 235-241.

Aiken, L.H., Sermeus, W., Vanden Heede, K., et al. (2012). Patient safety, satisfaction, and quality of hospital care: cross-sectional surveys of nurses and patients in 12 countries in Europe and the United States. BMJ, 344, e1717.

Alhassan, R.K., Duku, S.O., Janssens, W., Nketiah-Amponsah, E., Spieker, N., van Ostenberg, P., et al. (2015). Comparison of Perceived and Technical Healthcare Quality in Primary Health Facilities: Implications for a Sustainable National Health Insurance Scheme in Ghana. PLoS One, 10(10), e0140109. doi: 10.1371/journal.pone.0140109.

Babiarz, P., Grabinski, T., Migala-Warchol, A., \& Szczygiel, E. (2018). The application of customized human development index to the analysis of socioeconomic development of the European Union member states. Economics \& Sociology, 11(4), 332-342.

Berman, B. (2000). Organization of ambulatory care provision: a critical determinant of health system performance in developing countries. Bulletin of the World Health Organization, 78(6), 791-802.

Bloom, D.E., Canning, D., \& Fink, G. (2014). Disease and development revisited. Journal of Political Economy, 122(6), 1355-1366, doi: 10.1086/677189.

Boachie, M.K. (2017). Health and economic growth in Ghana: An empirical investigation. Fudan Journal of the Humanities and Social Sciences, 10(2), 253-265.

Bris, P., Keclikova, K., Macuda, M., \& Cermakova, M. (2016). Healthcare Quality Management in Great Britain and Czech Republic. Economics and Sociology, 9(3), 169179, doi: 10.14254/2071-789X.2016/9-3/15.

Cornell University, INSEAD, WIPO (2018). The Global Innovation Index 2018: Energizing the World with Innovation. Ithaca, Fontainebleau, and Geneva.

Dagger, T.S., Sweeney, J.C., \& Johnson, L.W. (2007). A hierarchical model of health service quality: Scale development and investigation of an integrated model. Journal of Service Research, 10(2), 123-142, doi: 10.1177/1094670507309594.

De Vaus, D.A. (2002). Surveys in social research. (5th Ed.). St Leonards, NSW: Allen \& Unwin.

Doyle, C., Lennox, L., \& Bell, D. (2013). A systematic review of evidence on the links between patient experience and clinical safety and effectiveness. BMJ Open, 3(1), e001570, doi: 10.1136/bmjopen-2012-001570.

Doubova, S.V., \& Pérez-Cuevas, R. (2018). Going further to measure improvements in health-care access and quality. The Lancet, 391(10136), 2190-2192.

EC, European Commission. (2016). Joint Report on Healthcare and Long-Term Care Systems and Fiscal Sustainability. Institutional Paper 37 available at http://www.ihealth.sk/analyzy/1619_analyza-ineko-ako-slovensko-zaplati-za-neliecenie-

zdravotnictva. 
Fedorko R., Bačík R., \& Kerul'ová V. (2017). The analysis on the importance of the reputation management in relation to e-commerce subjects. Polish Journal of Management Studies, 15, 48-56

Fernandes, O.B., Baji, P., Kringos, D., Klazinga, N., Gulacsi, L., Lucevic, A., Boncz, I., \& Pentek, M. (2019). Patient experiences with outpatient care in Hungary: results of an online population survey. European Journal of Health Economics, 20(Suppl. 1), S79S90, doi: 10.1007/s10198-019-01064-z.

Gallardo-Albarran, D. (2018). Health and economic development since 1900. Economics \& Human Biology, 31, 228-237, doi: 10.1016/j.ehb.2018.08.009.

Gonos, J., Timkova, V., \& Kosikova, M. (2018). Examining differences in job satisfaction in the Slovak Republic. Quality - Access to Success, 19(163), 65-69.

Gorgulu, O. (2018). Determination of the relationship between patient satisfaction and some global economic indicators using multidimensional scaling. Nigerian Journal of Clinical Practice, 21(11), 1422-1429, doi: 10.4103/njcp.njcp_218_17.

Grytten, J., Carlsen, F., \& Skau, I. (2009). Services production and patient satisfaction in primary care. Health Policy, 89(3), 312-321.

Hartwig, J. (2010). Is health capital formation good for long-term economic growth? - Panel Granger-causality evidence for OECD countries. Journal of Macroeconomics, 32(1), 314-325, doi: 10.1016/j.jmacro.2009.06.003.

Hult, K.J., Jaffe, S., \& Philipson, T.J. (2018). How does technological change affect qualityadjusted prices in healthcare? Systematic evidence from thousands of innovations. American Journal of Health Economics, 4(4), 433-453.

Ivanová, E., \& Čepel, M. (2018). The Impact of Innovation Performance on the Competitiveness of the Visegrad 4 Conutries. Journal of Competitiveness, Vol. 10, Issue 1, pp. 54-72. doi: 10.7441/joc.2018.01.04

Yagudin, R.Kh., Yurkov, D.V., Yakunina, R.P., \& Vishnjakov, N.I. (2016). The impact of health capital on results of correlation analysis which constitute human development in the regions of the Russian federation. Globalization and Its Socio-Economic Consequences, 16th International Scientific Conference Proceedings, Pts I-V, 24422447.

Jenkinson, C., Coulter, A., Bruster, S., Richards, N., \& Chandola, T. (2002). Patients' experiences and satisfaction with healthcare: results of a questionnaire study of specific aspects of care. Quality \& Safety in Healthcare, 11(4), 335-339.

Kim, D., Wu, Y., \& Lin, S. (2019). Education, Health, and Economic Development. Macroeconomic Dynamics, 23(2), 837-869, doi: 10.1017/S1365100517000050.

Kiselakova, D., Sofrankova, B., Gombar, M., Cabinova, V., \& Onuferova, E. (2019). Competitiveness and Its Impact on Sustainability, Business Environment, and Human Development of EU (28) Countries in terms of Global Multi-Criteria Indices. Sustainability, 11(12), 1-25. doi: 10.3390/su11123365

Kiselakova, D., Sofrankova, B., Cabinova, V., Onuferova, E., \& Soltesova, J. (2018). The Impact of R\&D Expenditure on the Development of Global Competitiveness within the CEE EU Countries. Journal of Competitiveness, 10(3), 34-50. https://doi.org/10.7441/joc.2018.03.03

Ko, D.G., Mai, F., Shan, Z., \& Zhang, D. (2019). Operational efficiency and patient-centered healthcare: A view from online physician reviews. Journal of Operations Management, 65(4), 353-379, doi: 10.1002/joom.1028.

Kotulic, R. (2013). Demographic changes and their impact on human resources - employment in Slovakia. Polish Journal of Management Studies, 5, 245-253. 
Krot, K., \& Rudawska, I. (2017). Patients' Trust in Physiciants as an Antecedent of Satisfaction with Medical Servcies. Economics and Sociology, 10(2), 207-216. doi:10.14254/2071-789X.2017/10-2/15

Łakomy-Zinowik, M., \& Horváthová, Z. (2016). Public-private partnerships as a way of financing in the healthcare system (based on the examples of Poland and the United Kingdom). Journal of International Studies, 9(3), 150-158. doi:10.14254/20718330.2016/9-3/12

Lange, S., \& Vollmer, S. (2017). The effect of economic development on population health: a review of the empirical evidence. British Medical Bulletin, 121(1), 47-60.

McMullen, M., \& Netland, P.A. (2013). Wait time as a driver of overall patient satisfaction in an ophthalmology clinic. Clinical Ophthalmology, 7, 1655-1660, doi: 10.2147/OPTH.S49382.

Mickan, S., Tilson, J.K., Atherton, H., Roberts, N.W., \& Heneghan, C. (2013). Evidence of effectiveness of healthcare professionals using handheld computers: a scoping review of systematic reviews. Journal of Medical Internet Research, 15(10), 111-119.

Mosadeghrad, A.M. (2013). Healthcare service quality: towards a broad definition. International Journal of Healthcare Quality Assurance, 26(3), 203-219.

Murante, A.M., Seghieri, C., Vainieri, M., \& Schäfer, W.L.A. (2017). Patient-perceived responsiveness of primary care systems across Europe and the relationship with the health expenditure and remuneration systems of primary care doctors. Social Science \& Medicine, 186, 139-147.

NUMBEO, (2018). Available at https://www.numbeo.com/health-care/

Obrizan, M., \& Wehby, G.L. (2018). Health Expenditures and Global Inequalities in Longevity. World Development, 101, 28-36.

OECD. (2012). Health at a Glance: Europe 2012 (Consultations with doctors).

OECD. (2016). Health at a Glance: Europe 2016: State of Health in the EU Cycle. OECD Publishing, Paris.

Price, R.A., Elliott, M.N., Zaslavsky, A.M., Hays, R.D., Lehrman, W.G., Rybowski, L., Edgman-Levitan, S., \& Cleary, P.D. (2014). Examining the role of patient experience surveys in measuring healthcare quality. Medical Care Research and Review, 71(5), 522-554.

Ross, C.K., Steward, C.A., \& Sinacore, J.M. (1993). The importance of patient preferences in the measurement of health-care satisfaction. Medical Care, 31(12) 1138-1149.

Rousseeuw, P.J. (1987). Silhouettes: A Graphical Aid to the Interpretation and Validation of Cluster Analysis. Journal of Computational and Applied Mathematics, 20, 53-65.

Sharma, R. (2018). Health and economic growth: Evidence from dynamic panel data of 143 years. PLoS One, 13(10), doi: 10.1371/journal.pone.0204940.

Simionescu, M., Bilan, S., Gavurova, B., \& Bordea, E. N. (2019). Health Policies in Romania to Reduce the Mortality Caused by Cardiovascular Diseases. International journal of environmental research and public health, 16(17), 3080.

Sofrankova, B., Kiselakova, D., Cabinova, V., \& Onuferova, E. (2018). R\&D Expenditure as a Factor of the Competitiveness and Innovation Activity Development within the V4 Countries. Innovation Management and Education Excellence through Vision 2020, Vols I -Xi, 31st International-Business-Information-Management-Association Conference, pp. 4811-4821.

Steffen, G. E. (1988). Quality Medical Care: A Definition. JAMA. 260(1), 56-61.

Tambor, M., Pavlova, M., Woch, P., \& Groot, W. (2011). Diversity and dynamics of patient cost-sharing for physicians' and hospital services in the 27 European Union countries. European Journal of Public Health, 21(5), 585-590. 
Toth, F. (2018). Integration vs separation in the provision of healthcare: 24 OECD countries compared. Health economics, policy, and law. 1-13.

UNDP, (2017). Human Development Report 2016: Human Development for Everyone. UN, New York.

Ursoiu, A.B. (2018). Patient Satisfaction Focused Healthcare - The Importance of Adapting the Marketing Mix to the Orientations in the National Healthcare Systems. Proceedings Paper of 6th International Conference on Marketing and Business Development (MBD), 1(1), 30-36.

Varabyova, Y., \& Schreyögg, J. (2013). International comparisons of the technical efficiency of the hospital sector: Panel data analysis of OECD countries using parametric and nonparametric approaches. Health Policy, 112(1-2), 70-79.

Wang, F. (2018). The roles of preventive and curative healthcare in economic development. PLoS One. 13(11).

Weil, D.N. (2007). Accounting for the effects of health on economic growth. Quarterly Journal of Economics, 122(3), 1265-306, doi:10.1162/qjec.122.3.1265.

WHO, (2012). Evaluation of the structure and provision of primary care in Slovakia: A survey-based project. World Health Organization (WHO), April 2012.

Williams, B. (1994). Patient satisfaction: A valid concept? Social Science \& Medicine, 38(4) 509-516.

World Health Organisation. Make every mother and child count. The World Health Report. 2005.

Xesfingi, S., \& Vozikis, A. (2016). Patient satisfaction with the healthcare system: Assessing the impact of socio-economic and healthcare provision factors. BMC Health Services Research, 16(1), doi: 10.1186/s12913-016-1327-4 